\title{
DOCUMENTAÇÃO PEDAGÓGICA NA EDUCAÇÃO INFANTIL: TECNOLOGIA DE GOVERNAMENTO DA INFÂNCIA CONTEMPORÂNEA
}

\author{
PRACTICES OF RECORDING PEDAGOGICAL DOCUMENTS IN CHILD \\ EDUCATION: A TECHNOLOGY OF GOVERNMENT OF \\ CONTEMPORARY CHILDHOOD
}

\section{PRÁCTICAS DE REGISTRO DE LA DOCUMENTACIÓN PEDAGÓGICA EM LA EDUCACIÓN INFANTIL: TECNOLOGÍA DE GOBERNACIÓN DE LA INFANCIA CONTEMPORÁNEA}

Cláudia Inês Horn ${ }^{1}$, Elí Terezinha Henn Fabris ${ }^{2}$

\begin{abstract}
RESUMO
Este trabalho analisa como as práticas de registro da documentação pedagógica operam no governamento da infância contemporânea. Ao desenvolver-se um exercício analítico a partir da seleção de referenciais italianos para Educação Infantil, apresentam-se os fundamentos da documentação pedagógica, a fim de mostrar como ela produz um gradual refinamento nas formas de registrar as ações da criança, fazendo surgir um registro rigoroso, pontual e completo do sujeito infantil. Entende-se que tal forma de registro, ao subjetivar a criança, produz outros modos de viver a infância, condizentes com as formas de vida neoliberais. Toma-se o conceito foucaultiano de governamento para argumentar que a infância é governada por meio da invenção de saberes, programas, estratégias e táticas que conduzem a conduta das crianças. Nesse sentido, a documentação pedagógica é compreendida como tecnologia que articula um conjunto de estratégias que governam a infância. Na parte final, argumenta-se que, ao colocar-se a criança no centro do processo educativo, o interesse infantil passa a operar como uma estratégia que se desloca, atualmente, para a celebração da criança protagonista. Há uma economia nas ações pedagógicas e o esmaecimento do ensino e da ação do professor em favor da criança autorregulada.
\end{abstract}

PALAVRAS-CHAVE: Infância. Governamento. Documentação pedagógica. Interesse. Protagonismo infantil.

\begin{abstract}
This paper analyzes the way in which the practices of recording pedagogical documents act in the government of contemporary childhood. Through an analytical exercise considering a selection of Italian references for Child Education, we present the foundations of pedagogical documentation, in order to show how it produces a gradual refinement of the ways of recording children's actions, thus giving rise to a strict, punctual and thorough record of the child subject. We understand that such kind of record, by subjectifying the child, produces ways of experiencing childhood that are compatible with the neoliberal living styles. We have taken the Foucauldian concept of government to argue that childhood has been governed by means of the invention of knowledge, programs, strategies and tactics that conduct the children's conduct. In this sense, the pedagogical documents are understood as a technology that articulates a set of strategies that govern
\end{abstract}

\footnotetext{
${ }^{1}$ Doutoranda em Educação - Universidade do Vale do Rio dos Sinos (UNISINOS). São Leopoldo, RS - Brasil. Docente do Centro de Ciências Humanas e Sociais do Centro Universitário - Universidade em Lajeado, Rio Grande do Sul (Univates) - Lajeado, RS - Brasil. E-mail: clauhorn@yahoo.com.br

${ }^{2}$ Doutorado em Educação - Universidade Federal do Rio Grande do Sul (UFRGS). Porto Alegre, RS - Brasil. Professor Adjunto II - PJII da Universidade do Vale do Rio dos Sinos (UNISINOS). São Leopoldo, RS -

Brasil. E-mail: efabris@unisinos.br
}

Submetido em: 30/06/2016 - Aceito em: 23/03/2018

(C) ETD-Educação Temática Digital Campinas, SP $\quad$ v.20 $\quad$ n.2 $\quad$ p. 539-554 abr./jun. 2018


childhood. Finally, we argue that, by placing the child in the center of the educational process, the child interest works as a strategy that has been currently displaced to the celebration of the protagonist child. There is economy of pedagogical actions and a reduction of both teaching and teachers' actions in favor of the selfgoverned child.

KEYWORDS: Childhood. Government. Pedagogical documentation. Interest. Child protagonism.

\section{RESUMEN}

Este trabajo analiza cómo las prácticas de registro de la documentación pedagógica operan en la gobernación de la infancia contemporánea. Al desenvolverse un ejercicio analítico a partir de la selección de referenciales italianos para la educación infantil, se presentan los fundamentos de la documentación pedagógica, con el fin de mostrar cómo esta produce un refinamiento gradual en las formas de registrar las acciones de los niños, haciendo surgir un registro riguroso, puntual y completo de cada individuo. Se entiende que tal forma de registro, al subjetivar al niño, produce otros modos de vivir la infancia, que condice con las formas de vida neoliberales. Se toma el concepto foucaultiano de gobernación para argumentar que la infancia es dirigida por medio de la invención de saberes, programas, estrategias y tácticas que conducen a la conducta de los niños. En este sentido, la documentación pedagógica es comprendida como una tecnología que articula un conjunto de estrategias que gobiernan la infancia. En la parte final, se argumenta que, al colocar al niño en el centro del proceso educativo, el interés infantil pasa a operar como una estrategia que se desarticula, actualmente, para celebrar al niño como protagonista. Hay una economía en las acciones pedagógicas y una reducción de la enseñanza y de la acción del profesor a favor del niño autoregulado.

PALABRAS CLAVE: Infancia. Gobernación. Documentación pedagógica. Interés. Protagonismo infantil.

\section{INTRODUÇÃO}

O foco do presente artigo $^{3}$ está em mostrar como as práticas de registro denominadas de "documentação pedagógica" operam como tecnologia no governamento da infância contemporânea. Para sustentar tal argumentação, inicialmente, será necessário compreender alguns referenciais da documentação pedagógica - prática de registro docente colocada em ação a partir de referenciais teóricos, especialmente das produções italianas voltadas à Educação Infantil. Nossa hipótese é a de que tais práticas produzem um gradual refinamento nas formas de registrar as ações das crianças na escola, ou seja, emerge um registro rigoroso, pontual e completo do sujeito infantil. Entendemos que esta forma de registro, ao subjetivar as crianças da Educação Infantil e também os professores desse nível de ensino, estaria produzindo outras subjetividades infantis condizentes com as formas de vida ajustadas à racionalidade neoliberal contemporânea. Assim, as estratégias colocadas em ação por essa tecnologia produzem sujeitos bastante particulares no tempo atual.

Numa perspectiva foucaultiana, compreendemos que a infância é governada por meio da invenção de uma série de saberes, programas, estratégias e táticas que conduzem a vida das crianças e também a vida dos adultos em relação às crianças, tudo atravessado por múltiplas, diferenciadas e intensas relações de poder. O governamento da infância dá-se

\footnotetext{
${ }^{3}$ Este artigo apresenta um recorte da Tese de Doutorado intitulada "Documentação Pedagógica: a produção da criança protagonista e do professor designer" (HORN, 2017).
} 
mediante certa racionalização nas formas de agir sobre as ações dos outros para alcançar determinados fins (ROSE, 2011), mas opera também nas formas de agir que afetam a maneira como os próprios indivíduos conduzem a si mesmos (BUJES, 2008).

Nesse sentido, as práticas de registro docente são compreendidas como tecnologia de poder que articula um conjunto de estratégias que governam a infância contemporânea. Com este artigo, pretendemos mostrar como a centralidade na aprendizagem da criança coloca em ação um conjunto de estratégias bastante sutis e refinadas, ligadas às tramas das racionalidades neoliberais. Uma dessas estratégias é a do interesse infantil, que hoje ganha relevância e se adéqua à celebração da criança protagonista. Com certo deslocamento nas formas de governamento da infância contemporânea, percebemos uma economia nas ações pedagógicas e um esmaecimento do ensino e da ação do adulto enquanto professor, em favor de uma criança que ocupa o centro do processo educativo e cujos interesses funcionam como potentes estratégias para acionar o protagonismo infantil, cuja celebração passa a ser pauta tanto da educação quanto da vida social contemporânea. Pretendemos deixar essas questões mais claras no decorrer da escrita, entretanto, duas ressalvas são importantes antes de apresentarmos a próxima seção.

A primeira: a expressão "documentação pedagógica" emerge da seleção de um conjunto de referenciais italianos para a educação da infância, a saber: Edwards, Gandini e Forman (1999; 2016); Rabitti (1999); Gandini e Goldhaber (2002); Dahlberg, Moss e Pence (2003); Kinney e Wharton (2009); Fortunati (2009; 2014); Luff (2010); Gandini, Hill, Cadwell e Schwall (2012); Rinaldi (2012); Ceppi e Zini (2013). Embora saibamos que nem todos os autores dessas obras são de origem italiana, resolvemos reuni-los numa única expressão, pois o que os conecta é o interesse em conhecer e estudar mais sobre as diferentes propostas de Educação Infantil oferecidas em inúmeras cidades italianas: Reggio Emilia, San Miniato, Parma, Firenze, Bolonha e Pistoia, entre outras. Apesar de ser possível reconhecer a presença dos registros sobre as crianças muito antes dos referenciais italianos, é visível que eles têm impacto nas escolas e fazem movimentar outras possibilidades de registro, incluindo filmagens, fotografias e transcrição de falas das crianças, entre outros recursos, primando pela rapidez na sua forma de comunicação e possibilidade de registro de instantâneos da rotina escolar infantil.

Segunda ressalva: queremos deixar claro que não nos propomos o exercício de posicionarmo-nos contra a documentação pedagógica, pois entendemos que essa posição não nos deixaria vasculhar as "entranhas" de tais práticas; queremos, sim, seguir os passos de sua constituição como uma verdade naturalizada como a mais eficiente, qualificada e, de certa maneira, a que passa a ser naturalizada como "a melhor" forma de registro das aprendizagens infantis na Contemporaneidade. Assim, ao estudarmos criteriosamente a abordagem italiana para as práticas de registro da documentação pedagógica, desenvolvemos um exercício analítico que tem como objetivo maior pensar sobre as

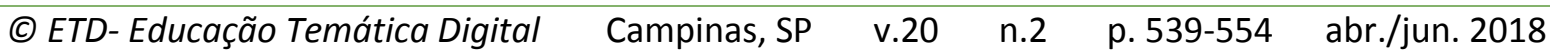


seguintes questões: "que estão os outros fazendo de nós?" e "que estamos nós fazendo de nós mesmos?", conforme expõe Veiga-Neto (2011, p. 12), referenciando Nietzsche. Portanto, trata-se de problematizar os modos pelos quais nos constituímos sujeitos do nosso tempo e, especificamente, como estamos contribuindo para a constituição dos sujeitos infantis deste tempo, como professores da infância contemporânea.

\section{O GOVERNAMENTO DA INFÂNCIA E AS PRÁTICAS DA DOCUMENTAÇÃO PEDAGÓGICA}

'Conhecer' um objeto de tal maneira que ele possa ser governado é mais do que
uma atividade puramente especulativa: exige a invenção de procedimento de
notação, modo de coletar e de apresentar estatísticas, o transporte destas para
outros centros onde se possam fazer cálculos e avaliações, e assim por diante.

(MILLER; ROSE, 2012, p. 44)

A epígrafe acima nos faz pensar que, para governar a infância, foi necessário criar uma série de prescrições, períodos de desenvolvimento infantil, cálculos, estatísticas, avaliações, entre outros saberes capazes de sustentar conhecimentos minuciosos sobre a infância.

Quando nos referimos à infância enquanto categoria histórico-social, queremos marcar a sua invenção na Modernidade, período em que houve a preocupação em criar uma série de prescrições e determinações do que é ser criança e, como diversos autores afirmam, quando sua construção histórica foi datada, pensada, administrada, regulada e "inventada" (VARELA, 2000; NARODOWSKI, 2001; BUJES, 2002; KOHAN, 2005; 2007; LARROSA, 2011). Na invenção de uma categoria bastante particular - a infância -, inventamos estatísticas e saberes médicos, psicológicos e pedagógicos, entre outros próprios dos "experts do particular", e as crianças começam a tornar-se alvo de uma série de programas (Ó, 2009). Ao lado da invenção de um sentimento de infância, começa a existir uma pedagogia interessada na infância, buscando "estudar e conhecer as crianças, seu corpo, seus desejos, seus brinquedos, seu pensamento, suas capacidades intelectuais", e os saberes e poderes passam a "produzir um tipo específico de criança, uma forma particular de subjetividade infantil" (KOHAN, 2005, p. 94).

Tratar da infância, portanto, é estar atento às formas de governamento. Conforme cita Carvalho, "para haver governo da infância, foi necessário criá-la como objeto de análise, de classificação e de diferenciação (2015, p. 26). A partir da análise que desenvolvemos neste trabalho, percebemos que as práticas de documentação pedagógica que emergem com os referenciais italianos, cuja ênfase está na centralidade da criança, tendem a produzir outros modos de viver a infância contemporânea. Contudo, ao problematizarmos o governamento da infância, não queremos dizer que isso é, por si só, bom ou ruim. Quando Foucault diz que "nem tudo é ruim, mas tudo é perigoso, o que não significa exatamente o mesmo que ruim" (FOUCAULT, 2010, p. 299), é possível usar esse mesmo argumento para a

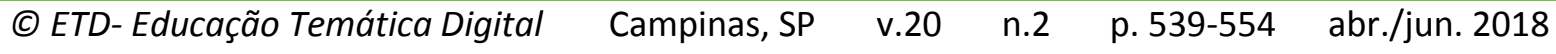


ideia de que governar a infância e as crianças é perigoso, mas não é possível definir a priori nem como positivo, nem como negativo. A questão central a ser tensionada é como estamos governando a infância e as crianças para, como afirma Veiga-Neto, "saber para onde essas formas de governamento as estão levando" (VEIGA-NETO, 2015, p. 56), ou ainda, como nós, professores contemporâneos, auxiliamos nessa condução da infância e das crianças e delas sobre si mesmas. Tal como propõe Foucault, "se tudo é perigoso, então sempre temos algo a fazer" (FOUCAULT, 2010, p. 299).

Pesquisas (FABRIS; TRAVERSINI, 2013; SILVA, FABRIS, 2016) têm apontado que, na Contemporaneidade, as práticas que mais circulam nas escolas esmaecem a disciplina e a correção e fazem circular outras práticas que uma sociedade de seguridade coloca em circulação, entre elas, os cuidados e a prevenção dos riscos sociais. Tais análises indicam que o Estado vive outra configuração e que as funções das instituições escolares passam a ser outras. O conceito de governamento ${ }^{4}$ ajuda-nos a entender como os sujeitos agem sobre si mesmos, autorregulando suas vidas desde tenra idade. As crianças não ficam imunes a essa racionalidade, nem mesmo aquelas que frequentam a Educação Infantil. A criança de 0 a 5 anos também é convocada a adquirir gradativamente mais liberdade e autonomia para fazer suas próprias escolhas e passa a investir nos seus interesses a fim de empreender sua própria aprendizagem. E é justamente no investimento de um sujeito infantil autônomo, livre, responsável pela sua própria educação, empreendedor e inovador, que encontramos frestas para pensar a criança da Educação Infantil do nosso tempo.

A partir das considerações e argumentos até aqui expostos, acreditamos que temos algo a fazer em relação às práticas de registro docente. Mesmo que de forma breve, neste artigo, queremos mostrar as lógicas de funcionamento das práticas da documentação pedagógica - fundamentos, estratégias, recursos, bem como a imagem de criança que circula nessa abordagem - a fim de perceber a sua articulação com a produção da infância contemporânea.

As três funções da abordagem da documentação pedagógica comuns às narrativas postuladas nos referenciais italianos analisados, resumidamente, são: oferecer às crianças uma memória concreta e visível daquilo que disseram e fizeram na escola em relação à aprendizagem; oferecer aos educadores uma ferramenta para pesquisa e renovação contínua; e oferecer aos pais e ao público informações detalhadas sobre os acontecimentos na escola. Poderíamos dizer, grosso modo, que essas três funções são evidenciadas em quase todos os referenciais italianos analisados - "aquilo que é documentado pode ser visto

\footnotetext{
${ }^{4}$ Veiga-Neto (2005) esclarece alguns problemas com o vocabulário técnico e propõe a ressurreição, na língua portuguesa, da palavra governamento para entender a ideia de governo na perspectiva foucaultiana: ação de conduzir as condutas de uns sobre os outros ou sobre si mesmo, marcando os dois eixos de governamento, ou seja, entre sujeitos e consigo próprio (VEIGA-NETO, 2005).
} 
como uma narrativa das vidas das crianças, dos professores e dos pais" (EDWARDS, GANDINI, FORMAN, 2016, p. 233). Assim, crianças, professores e pais formam o tripé da documentação pedagógica, ou ainda, uma comunidade de aprendizagem - uma comunidade que assegura as funções da documentação pedagógica e que coloca em ação estratégias para que as crianças possam tornar-se protagonistas. Pais e professores acionam essas estratégias para que as crianças se autorregulem e, assim, assumam o comando de suas vidas e da vida social.

A ideia de sistematização toma destaque em tal abordagem, como aponta Malaguzzi (1999, p. 80): os professores "devem descobrir modos de comunicar e documentar as experiências crescentes das crianças na escola, devendo preparar um fluxo constante de informações de qualidade, voltado aos pais, mas também apreciado pelas crianças e pelos professores". Sistematização e fluxo constante são marcas dessa nova forma de registro docente. Como podemos acompanhar, a dedicação de Malaguzzi à educação das crianças de Reggio Emilia/Itália e sua preocupação com a construção e manutenção de escolas infantis de qualidade transitam num sentimento de pós-guerra, e é nesse contexto que o autor desencadeia e impulsiona a prática - ou o instrumento metodológico - da documentação pedagógica.

A partir da análise dos referenciais italianos, percebemos que a documentação pedagógica pretende contrastar com práticas modernistas de avaliação convencional, em que a criança era avaliada e classificada segundo categorias e estágios predeterminados de desenvolvimento psicológico, uma vez que a documentação possibilita a autorreflexão dos adultos em relação às crianças, e mais, ela "diz respeito principalmente à tentativa de enxergar e entender o que está acontecendo no trabalho pedagógico e o que a criança é capaz de fazer sem qualquer estrutura predeterminada de expectativas e normas" (DAHLBERG; MOSS; PENCE, 2003, p. 192). A documentação também pretende fugir da ideia de mensuração presente em algumas práticas avaliativas, compreendida como uma ciência exata que avalia quantidades mediante unidades padronizadas de medida, tendo caráter somativo de atribuir notas e comparar alunos, classificando-os "em uma escala para determinar o nível de competência ou desenvolvimento, classificá-los para serviços especiais ou decidir em reprová-los ou passá-los à próxima série" (FYFE, 2016, p. 279). Já a documentação consiste em "traços de aprendizagem", e "nenhum traço de aprendizagem é limitado em sua interpretação a uma unidade de medida padronizada" (FYFE, 2016, p. 274). Portanto, as avaliações formais não fazem parte do conceito de documentação de Reggio Emilia, afirma a autora, uma vez que a documentação "é conduzida de modo a estimular o aprendiz a participar da própria aprendizagem para construir ou reconstruir novas e mais profundas compreensões" (FYFE, 2016, p. 274).

As práticas da documentação pedagógica emergem com força na Educação Infantil brasileira, marcando um tempo em que a primeira etapa da Educação Básica é convidada a

$\begin{array}{llllll}\text { (C) ETD-Educação Temática Digital } & \text { Campinas, SP } & \text { v.20 } & \text { n.2 } & \text { p. 539-554 } & \text { abr./jun. } 2018\end{array}$


elaborar e demarcar especificidades na sua proposta pedagógica, legitimando seu papel social. Se a documentação pedagógica é tomada como meio avaliativo que busca evitar avaliações padronizadas, descontextualizadas e objetivas que valorizam mais os resultados e os estágios de desenvolvimento psicológico, tal prática é sustentada pela construção de uma nova concepção de criança, não mais passiva, mas competente, ativa, protagonista e repleta de direitos sociais. Há um encaixe dos referenciais da documentação com a infância do nosso tempo. Tudo isso se conecta com outros modos de fazer a avaliação das crianças, vinculando inovação na Educação Infantil, ou seja, a documentação pedagógica vem sendo tomada como um modo inovador de avaliação, o que inclui filmagens, fotografias, transcrição de falas das crianças, entre outros recursos, primando pela rapidez na sua forma de comunicação e possibilidade de registro de instantâneos da rotina cotidiana escolar. Descrevemos tudo isso para explicitar alguns referenciais que sustentam as práticas da documentação pedagógica nas obras italianas e, a seguir, evidenciar como o interesse infantil constitui-se como uma estratégia de governamento da infância que, contemporaneamente, se encaixa e se adéqua à celebração da criança protagonista.

\section{O INTERESSE INFANTIL E O PROTAGONISMO DA CRIANÇA}

A criança é compreendida nos referenciais italianos analisados neste trabalho como um ser competente, ativo, criativo, ator e protagonista de suas ações, desafiador, um sujeito com direitos e voz, com potencial para fazer as suas próprias escolhas. Essa criança deve ocupar a centralidade nos processos escolares, a partir dos seus interesses infantis. 0 interesse infantil é entendido por nós como estratégia que mobiliza o governamento da infância e que vem se reconfigurando e se deslocando para o protagonismo infantil. Dito de outro modo, a celebração da criança protagonista encontra no interesse infantil a sua sustentação e a sua reconfiguração, contemplando as crianças do nosso tempo. Vale ressaltar que esse modo de ser criança na escola nem sempre existiu, mas vem sendo produzido, especialmente desde o surgimento da psicologia e, no campo da educação brasileira, das pedagogias ativas, que passam a circular antes dos anos 30 , mas que emergiram em várias partes do mundo nessa década, com o movimento da Escola Nova. Esse movimento trouxe críticas à escola tradicional, propondo a valorização do desenvolvimento integral do indivíduo, sendo que o interesse passava a ser o foco do processo educativo. Tal como aponta Azevedo, "o que distingue a escola tradicional da escola nova não é, de fato, a predominância dos trabalhos de base manual e corporal, mas a presença, em todas as suas atividades, do fator psicobiológico do interesse". (AZEVEDO et al., 2010, p. 50).

Assim, entram em cena, de forma cada vez mais potente, as pedagogias para a pequena infância, com ênfase na centralidade da criança, destacando um sujeito infantil autorregulado, capaz de fazer suas próprias escolhas a partir dos seus interesses. Essas narrativas aparecem repetidas vezes nos excertos retirados dos referenciais italianos,

\begin{tabular}{|c|c|}
\hline (C) ETD- Educação Temática Digital & \\
\hline
\end{tabular}


Liberdade, oportunidade, interesse, escolha e flexibilidade parecem ser palavras de ordem, como reforçam as citações do quadro abaixo.

QUADRO 2 - No centro, as crianças protagonistas Fonte: Elaborado pelas autoras (2016). Grifos das autoras

[...] as crianças mostram-nos que sabem como caminhar rumo ao entendimento. Uma vez que as crianças sejam auxiliadas a perceber a si mesmas como autoras ou inventoras, uma vez que sejam ajudadas a descobrir o prazer da investigação, sua motivação e interesse explodem (MALAGUZZI, 1999, p. 76-77).

[...] às crianças são oferecidas e apresentadas listas de atividades planejadas cuidadosamente - atividades significativas, voltadas ao desenvolvimento de muitas linguagens - e pede-se que as crianças escolham. As crianças não são obrigadas a fazer alguma coisa, são convidadas a fazer, se recusarem uma atividade, outras lhes serão oferecidas (RABITTI, 1999, p. 154).

A presença de espaços organizados e de laboratórios - com muitos materiais organizados de modo racional e facilmente visíveis e acessíveis para todo o mundo - constitui o mapa de um território transparente e aberto, onde as crianças se orientam com suas próprias bússolas, sempre capazes de selecionar e de multiplicar as opções (FORTUNATI, 2009, p. 153).

Isso significa reconhecer que uma ampla série de oportunidades e experiências devem estar disponíveis para apoiar a participação das crianças e para auxiliar as maneiras como elas aprendem e se envolvem umas com as outras e com os adultos (KINNEY; WHARTON, 2009, p. 23).

[...] capazes de escolher entre várias oportunidades, especialmente quando o ambiente educacional coloca à disposição um contexto de experiências adequado para a exploração e ainda, quando o adulto não interpreta seu próprio papel de maneira direcionadora, mas ao contrário, consegue sustentar as ações entre os grupos e duplas (FORTUNATI, 2014, p.26).

Ao conceder centralidade à criança, o interesse infantil passa a conduzir as ações pedagógicas, inclusive as planejadas pelo adulto. Assim, o interesse infantil opera enquanto estratégia de governamento da infância por meio das práticas de documentação pedagógica, ou seja, o interesse infantil pode ser compreendido como uma eficiente estratégia de governamento da criança na escola infantil. Os processos escolares passam do coletivo para o individual, e é no indivíduo interessado e livre - aquele que é capaz de escolher entre várias oportunidades - que se dá a aprendizagem. Com Michel Foucault (2008), entendemos que a liberdade é a condição de existência para as relações de poder, sendo que as novas racionalidades de governo estão permeadas pela liberdade de escolha de um cidadão livre, autônomo e empreendedor de si mesmo. Ao dizer isso, pretendemos olhar para as práticas da documentação pedagógica como tecnologias de governamento da infância; ao atuarem no sujeito, ele mesmo passa a atuar sobre si na busca de liberdade e autonomia, sendo responsável pelas suas escolhas, ou seja, "os indivíduos podem ser governados através de sua liberdade para escolher" (MILLER; ROSE, 2012, p. 104). Parecenos que a individualidade da criança é marcada como "um tipo particular de individualismo

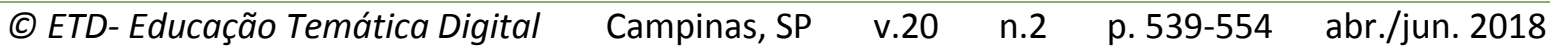


e um tipo particular de liberdade" (BALL, 2013, p. 149), destacando-se os seus interesses num vasto universo de materiais e recursos pedagógicos disponibilizados e organizados pelo professor, como "um eu que faz investimentos em atividades de gosto legitimado e um eu tomado como investimento" (BALL, 2013, p. 148).

Cabe ressaltar que muitas pedagogias se empenharam em mostrar o quanto o sujeito aprendente precisa ser ativo no seu processo de aprendizagem, apontando o interesse infantil como um elemento fundamental para o processo escolar. Retomamos brevemente Rousseau e Dewey, a fim de explicitar o quanto o interesse infantil não é um tema novo na educação das crianças pequenas. Entretanto, a partir de nossa análise dos referenciais italianos, percebemos novas nuances do próprio interesse, o que acaba produzindo outras roupagens para as crianças do nosso tempo, denominadas atualmente como protagonistas.

Retomando algumas ideias de Rousseau (1979), especialmente na obra $A$ Educação de Emílio, já acompanhávamos uma educação centrada na liberdade e nos interesses da criança, o que a faz ser compreendida como educação liberal, só sendo possível educar com liberdade (MARÍN-DÍAZ, 2010; NOGUERA-RAMÍREZ, 2011). Para Rousseau, a infância era a condição primeira na qual se desenvolvem e crescem as crianças, em "processos naturais que se devem respeitar, processos que têm sua própria temporalidade e que dão sentido à existência da infância como etapa inicial, na qual o homem se fortalece e aprende tudo o que precisa e que não foi dado nos instintos pela natureza" (NOGUERA-RAMÍREZ, 2011, p. 160). É nesse contexto que Rousseau pede que os adultos economizem as suas ações em função da ação da criança e que deem tempo para que ela se desenvolva em liberdade.

Conforme evidencia Noguera-Ramírez (2011) ao analisar as produções de Rousseau, não vemos mais a criança necessitar de uma ação direta do exterior, com um ensino exercido pelo mestre com um método, mas uma criança que deve aprender sem ser ensinada. Uma liberdade autorregulada: educar menos para que o outro faça mais, ou seja, há uma economia na educação. Porém, não se trata de uma educação fraca; pelo contrário, "a educação liberal é uma educação intensiva, permanente, constante, pois é uma educação da natureza, dos homens e das coisas" (NOGUERA-RAMíREZ, 2011, p. 163). Assim, a centralidade posta na criança pode ser lida como uma economia de governamento, isto é, o interesse infantil opera como estratégia de governamento, conduzindo uma autorregulação da criança, tal como nos referenciais italianos analisados.

Ao retomarmos Dewey (filósofo norte-americano considerado um dos pedagogos da Escola Nova), vemos que a palavra interesse ocupa centralidade em suas obras. O interesse estaria em estreita conexão com a palavra objetivo, propósito: "são resultados desejados que nos esforçamos por obter" (DEWEY, 1959, p. 137). Só tem interesse um ser ativo "que participa das conseqüências em vez de ficar estranho às mesmas, existe ao mesmo tempo

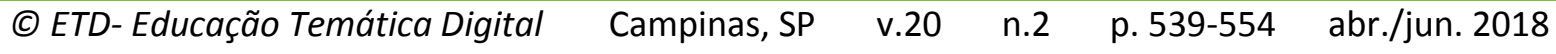


uma reação pessoal" (p. 137). O interesse é, para Dewey, a intensidade da influência do fim previsto para fazer uma pessoa empreender a sua realização, representando a força que faz mover os objetos (DEWEY, 1959). Ainda, o interesse é "a identificação ativa e operante do eu com certo objeto" (p. 386). Ele destaca que o interesse é sempre individual e está atrelado às preferências de cada criança. A instrução, portanto, deve encontrar materiais nos quais o educando aplique sua atividade e que tenham objetivos de seu interesse, ou seja, todas as atividades devem tomar o interesse do educando, permitindo liberdade intelectual.

Dewey coloca o interesse infantil como um meio para aprender e como uma possibilidade de o aluno adaptar-se, crescer e desenvolver-se. Interessado nos fundamentos de Dewey, Noguera-Ramírez diz que "o interesse garante a economia da ação, uma economia das forças, e a aprendizagem é a ação mais eficiente que um organismo pode conseguir" (NOGUERA-RAMÍREZ, 2011, p. 242). A abordagem de Dewey pretende trazer uma interioridade e uma individualização do interesse humano, ou seja, há pouco de exterioridade ao indivíduo e muito de interioridade. Esse modo de conceber o interesse do indivíduo, em especial, o interesse das crianças, mostra-nos outras formas de governamento da infância atuando na interioridade de cada indivíduo. É do interior do indivíduo que se dá um governamento muito mais efetivo e eficaz, capaz de regular externamente menos, mas de forma mais flexível, mais sutil, mais livre de coerções e restrições diretivas, por isso capaz de regular muito mais e com mais economia de educação. Fazemos essa retomada com o objetivo de mostrar como as pedagogias ativas se movimentam sobre uma mesma racionalidade, embora com nuances muito diferentes em cada momento histórico. Não podemos esquecer o tempo histórico que se movimenta desde os anos 30 até os dias atuais. Hoje temos outras formas de interesse nas atividades, apesar de a atividade ser uma marca que movimenta as práticas, entre elas, as pedagógicas. No contemporâneo, as crianças são acionadas por tecnologias virtuais ou presenciais que as mobilizam para as atividades; nesse sentido, a atividade passa a ser uma realidade na vida dessas crianças de forma intensa e permanente.

Nos referenciais italianos analisados, a criança precisa investir no seu interesse, na sua liberdade de escolha, na sua autonomia e independência para empreender sua própria aprendizagem na escola. E é justamente no investimento do sujeito autônomo, livre, responsável pela sua própria educação, empreendedor e inovador que encontramos frestas para pensar o protagonismo infantil celebrado nos referenciais italianos e nas escolas brasileiras. A criança protagonista é aquele sujeito que tem interesses em sua vida na escola. Isso tudo faz parte do novo quadro no qual a criança do nosso tempo é emoldurada. Trata-se de um governo da infância por meio da autorregulação da própria criança mediante a manifestação dos seus próprios interesses e as escolhas que ela é incitada a fazer a todo o momento na escola. Na maior parte dos livros revisados neste estudo, é possível visualizar a importância e a necessidade de o adulto possibilitar inúmeras oportunidades de escolha às

$\begin{array}{llllll}\text { (C) ETD-Educação Temática Digital } & \text { Campinas, SP } & \text { v.20 } & \text { n.2 } & \text { p.539-554 } & \text { abr./jun. } 2018\end{array}$


crianças. Dito de outro modo, não são os adultos que escolhem; eles apenas oferecem inúmeras possibilidades para que cada criança possa fazer a sua escolha a partir do seu interesse. Os espaços e materiais da escola infantil são cuidadosamente organizados pelo professor para despertar o interesse infantil. Assim, as crianças passam a ser vistas, a partir dos referenciais italianos, como protagonistas. Os adultos, por sua vez, devem reconhecer "o direito de cada criança de ser protagonista e elevar a curiosidade espontânea da criança ao nível mais alto", afirmam Dahlberg e Moss no prefácio de um dos livros (RINALDI, 2012, p. 33).

Visualizamos um deslocamento do interesse infantil como estratégia de governamento, que passa a produzir o protagonismo infantil, especialmente nas práticas de registro da documentação pedagógica, ou seja, os interesses são reconfigurados, agora, na produção e celebração do protagonismo infantil. Enquanto antes importava um registro mais centralizado no professor (como os referenciais entendem a avaliação tradicional), parece-nos que agora a própria criança se mostra e é incentivada a mostrar-se, sendo que se veem a todos e a cada um. A criança está na centralidade de todas as formas de registro e é ela que ocupa o eixo e a razão dos processos educativos. Não precisamos mais de crianças obedientes que têm no professor o seu mestre e autoridade, mas crianças que, junto com os professores e pais, compõem e compartilham processos de aprendizagem. 0 chamado protagonismo infantil nasce nesse contexto e tem integrado a gramática brasileira da Educação Infantil nos últimos anos.

\section{CONSIDERAÇÕES FINAIS}

As possibilidades de investigação desenvolvidas até aqui nos levam a pensar que as práticas da documentação pedagógica postuladas pelos referenciais italianos analisados operacionalizam um governamento centrado na autorregulação do sujeito infantil, que conquista gradativamente mais liberdade nos processos educacionais. Com o filósofo Michel Foucault, vimos que o governo liberal não renuncia ao governo, mas opera numa economia de governo: governa menos para governar mais, e a liberdade aparece como uma das artes mais refinadas de governar os vivos. Assim, o interesse infantil encontra-se no âmago dos processos educacionais contemporâneos, cuja centralidade está nas ações do sujeito infantil, agora protagonista, desde tenra idade, de sua aprendizagem na escola. O interesse infantil é, atualmente, reconfigurado e acionado como estratégia para produzir o protagonismo infantil.

Talvez seja produtivo seguir pensando aqui em como, ao compreender as novas racionalidades de governamento, as práticas de documentação pedagógica precisam garantir as liberdades de escolha infantis para continuarem operando como tecnologia de governamento da infância, produzindo e regulando indivíduos que são cada vez mais "livres para escolher", uma vez que os "indivíduos 'livres' e espaços 'privados' podem ser

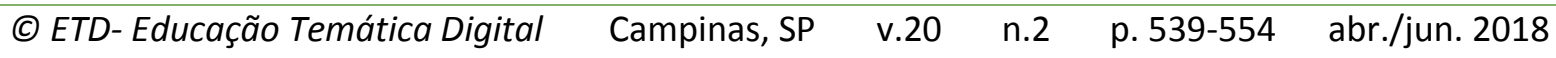


'governados' sem que se rompa sua autonomia formal" (MILLER; ROSE, 2012, p. 58). A criança protagonista é estimulada e incitada a tornar-se sujeito de sua própria aprendizagem, a avaliar suas conquistas, a aceitar ou rejeitar certas atividades e conteúdos escolares, assumindo responsabilidades por essas escolhas desde cedo.

Mais ainda, talvez seja prudente continuarmos a nos perguntar sobre a responsabilidade dos adultos na educação desses sujeitos infantis. Ao apenas acionar interesses para produzir sujeitos protagonistas, há um grande perigo de que essas crianças apostem sempre mais no empresariamento individual, baseado nos interesses de cada um. Que garantias para a consolidação de um espaço público estamos produzindo com uma educação para protagonistas de interesses individuais? Parece-nos que a documentação pedagógica, tal qual descrita pelos referenciais analisados neste exercício, pode não ser uma inocente inovação no ato de registrar e avaliar as produções infantis, e o que está fazendo é produzir sujeitos protagonistas de certo tipo, afinados com a racionalidade neoliberal. Talvez o pensamento hipercrítico possa ajudar-nos a continuar usando a documentação como registro e não dar a ela um estatuto de proposta de Educação Infantil. Acreditamos que, se tudo é perigoso, não temos saída a não ser pelo próprio pensamento, sempre afinado e profundo, para que se possa cortar a própria pele quando essa for a condição para proteger as crianças contemporâneas de uma vida social na qual o que importa são apenas seus interesses e seu protagonismo.

\section{REFERÊNCIAS}

AZEVEDO, Fernando de ... et al. Manifesto dos pioneiros da Educação Nova. Recife: Fundação Joaquim Nabuco/Massangana, 2010.

BALL, Stephen. Aprendizagem ao longo da vida, subjetividade e a sociedade totalmente pedagogizada. Educação, Porto Alegre, v. 36, n. 2, p. 144-155, mai./ago. 2013.

BUJES, Maria Isabel Edelweiss. Infância e maquinarias. Rio de Janeiro: P\&A, 2002.

BUJES, Maria Isabel Edelweiss. Artes de governar a infância: linguagem e naturalização da criança na abordagem de educação infantil da Reggio Emília. Educação em Revista, Belo Horizonte, Faculdade de Educação da Universidade Federal de Minas Gerais, n. 48, p. 101123, dez. 2008.

CARVALHO, Alexandre Filordi de. Por uma ontologia política da (d)eficiência no governo da infância. In: RESENDE, Haroldo de (org.). Michel Foucault: o governo da infância. Belo Horizonte: Autêntica, 2015. p. 25-48.

CEPPI, Giulio; ZINI, Michele (Orgs.). Crianças, espaços, relações: como projetar ambientes para a educação infantil. Porto Alegre: Penso, 2013.

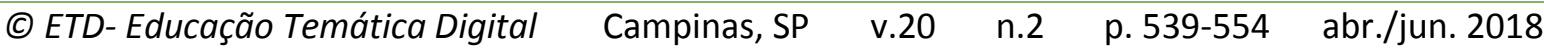


DAHLBERG, Gunilla; MOSS, Peter; PENCE, Alan. Qualidade na educação da primeira infância: perspectivas pós-modernas. Porto Alegre: Artmed, 2003.

DEWEY, John. Democracia e educação: introdução à Filosofia da Educação. 3 ed. São Paulo: Ed. Nacional, 1959.

EDWARDS, Carolyn; GANDINI, Lella; FORMAN, George. As cem linguagens da criança: a abordagem de Reggio Emilia na Educação da primeira infância. Porto Alegre: Calábria, 1999.

EDWARDS, Carolyn; GANDINI, Lella; FORMAN, George. As cem linguagens da criança: a experiência de Reggio Emilia em transformação. Porto Alegre: Penso, 2016.

FABRIS, Eli Terezinha Henn; TRAVERSINI, Clarice. Conhecimentos escolares sob outras configurações: efeitos das movimentações disciplinares e de controle? In: TRAVERSINI, Clarice et al. (Orgs.). Currículo e inclusão na escola de ensino fundamental. Porto Alegre: Edipucrs, 2013. p. 33-54.

FYFE, Brenda. A relação entre documentação e avaliação. In: EDWARDS, Carolyn; GANDINI, Lella; FORMAN, George. As cem linguagens da criança: a experiência de Reggio Emilia em transformação. Porto Alegre: Penso, 2016. p. 273-292.

FORTUNATI, Aldo. A educação infantil como projeto da comunidade. Porto Alegre: Artmed, 2009.

FORTUNATI, Aldo. A Abordagem de San Miniato para a educação das crianças:

protagonismo das crianças, participação das famílias e responsabilidade da comunidade por um currículo do possível. Itália: Edizioni ETS, 2014.

FOUCAULT, Michel. Segurança, Território, População. São Paulo: Martins Fontes, 2008.

FOUCAULT, Michel. O sujeito e o poder. In: DREYFUS, Hubert; RABINOW, Paul. Michel Foucault: uma trajetória filosófica. Rio de Janeiro: Forense, 2010. p. 231-249.

GANDINI, Lella; GOLDHABER, Jeanne. Duas reflexões sobre a documentação. In: GANDINI, Lella; EDWARDS, Carolyn (Orgs.). Bambini: A abordagem italiana à Educação Infantil. Porto Alegre: Artmed, 2002. p. 150-169.

GANDINI, Lella; HILL, Lynn; CADWELL, Louise; SCHWALL, Charles (Org.). O papel do ateliê na educação infantil: a inspiração de Reggio Emilia. Porto Alegre: Penso, 2012.

HORN, Cláudia Inês. Documentação Pedagógica: a produção da criança protagonista e do professor designer. 2017. 263f. Tese (Doutorado em Educação) - Programa de PósGraduação em Educação, Universidade do Vale do Rio dos Sinos (UNISINOS), São Leopoldo, 2017.

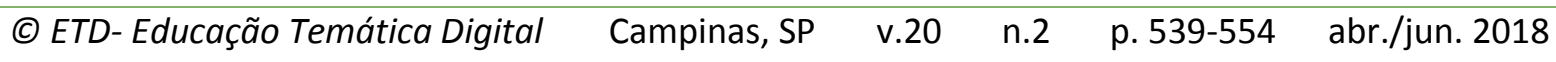


KOHAN, Walter O. A infância escolarizada dos modernos. In: KOHAN, Walter O. Infância: Entre Educação e Filosofia. Belo Horizonte: Autêntica, 2005.

KOHAN, Walter O. Infância, estrangeiridade e ignorância: ensaios de Filosofia e Educação. Belo Horizonte: Autêntica, 2007.

KINNEY, Linda; WHARTON, Pat. Tornando visível a aprendizagem das crianças. Porto Alegre: ARTMED, 2009.

LARROSA, Jorge. O enigma da infância - ou que vai do impossível ao verdadeiro. In: LARROSA, Jorge. Pedagogia Profana: danças, piruetas e mascaradas. Belo Horizonte: Autêntica, 2011. p. 183-198.

LUFF, Paulette. Observações escritas ou caminhadas pelo parque? Documentando as experiências das crianças. In: MOYLES, Janete (org.). Fundamentos da Educação Infantil: enfrentando o desafio. Porto Alegre: Artmed, 2010. p. 205-216.

MALAGUZZI, Lóris. História, Ideias e Filosofia Básica. In: EDWARDS, Carolyn; GANDINI, Lella; FORMAN, George. As cem linguagens da criança: a abordagem de Reggio Emilia na Educação da primeira infância. Porto Alegre: Calábria, 1999. p.59-104.

MANTOVANI, Susanna. Prefácio à Edição Italiana. In: FORTUNATI, Aldo. A educação infantil como projeto da comunidade. Porto Alegre: Artmed, 2009. p. 23-26.

MARÍN-DÍAZ, Dora. Morte da infância moderna ou construção da quimera infantil? Educação \& Realidade, Porto Alegre, v. 35, n. 3, p. 193-211, set./dez., 2010.

MILLER, Peter; ROSE, Nikolas. Governando o Presente. São Paulo: Paulus, 2012.

NARODOWSKI, Mariano. Infância e Poder: a conformação da Pedagogia Moderna. Bragança Paulista: Universidade São Francisco, 2001.

NOGUERA-RAMÍREZ, Carlos Ernesto. Pedagogia e governamentalidade: ou da modernidade educativa para uma sociedade educativa. Belo Horizonte: Autêntica, 2011.

Ó, Jorge Ramos do. A criança problema e o seu governo em Portugal e no Brasil (18801960): discursos e práticas. In: Ó, Jorge Ramos do; CARVALHO, Luís Miguel. Emergência e circulação do conhecimento psicopedagógico moderno (1880-1960): estudos comparados Portugal-Brasil. Lisboa: EDUCA, 2009. p. 15-147.

RABITTI, Giordana. À procura da dimensão perdida: uma Escola de Infância de Reggio Emilia. Porto Alegre: Artes Médicas, 1999. 
RINALDI, Carla. Diálogos com Reggio Emilia: escutar, investigar, aprender. São Paulo: Paz e Terra, 2012.

ROSE, Nikolas. Inventando nossos selfs: psicologia, poder e subjetividade. Petrópolis, RJ: Vozes, 2011.

ROUSSEAU, Jean-Jacques. Emílio ou da Educação. 3 ed. São Paulo: Difel, 1979.

SEIDEL, Steve. Começar em casa a compreender a documentar. In: ZERO, Project. Tornando visível a aprendizagem: crianças que aprendem individualmente e em grupo. São Paulo: Phorte, 2014. p. 310-319.

SILVA, Roberto Rafael Dias da; FABRIS, Elí Terezinha Henn. Políticas de currículo para o Ensino Médio no Brasil Contemporâneo: o que ensina aos jovens a escola que protege? Educação e Sociedade, Campinas, v. 37, n. 135, p. 425-443, abr-jun, 2016.

VARELA, Julia. Categorias espaço-temporais e socialização escolar: do individualismo ao narcisismo. In: COSTA, Marisa Vorraber (org.). Escola básica na virada do século: cultura, política e currículo. 2. ed. São Paulo: Cortez, 2000.

VEIGA-NETO, Alfredo. Governo ou governamento. Revista Currículo sem Fronteiras, v. 5, n. 02, p. 463-470, jul./dez. 2005.

VEIGA-NETO, Alfredo. Foucault \& a Educação. Belo Horizonte: Autêntica, 2011.

VEIGA-NETO, Alfredo. Por que governar a infância? In: RESENDE, Haroldo de (Org.). Michel Foucault: o governo da infância. Belo Horizonte: Autêntica, 2015. p. 49-56. 